\title{
Effect of Glutaraldehid on Human Amniotic Membrane Characteristics as Wound Dressing
}

\author{
Dian Marta Rizkawati ${ }^{1}$, Djony Izak R. ${ }^{2}$, Prihartini Widiyanti ${ }^{1,3}$ \\ ${ }^{1}$ Biomedical Engineering Study Program, Faculty of Science and Technology, \\ Universitas Airlangga, Surabaya, Indonesia \\ ${ }^{2}$ Physics Study Program, Faculty of Science and Technology, \\ Universitas Airlangga, Surabaya, Indonesia \\ ${ }^{3}$ Institute of Tropical Disease, Universitas Airlangga, Surabaya, Indonesia \\ Corresponding author: pwidiyanti@fst.unair.ac.id
}

Keywords: human amniotic membrane, glutaraldehyde, wound dressing

\begin{abstract}
The wound dressing which have good mechanical properties, non toxic, anti inflammation, anti infection and has potency to accelerate wound healing are important to be found. This study aimed to determine the effect of glutaraldehyde on the human amniotic membrane cross linking, tensile strength, material toxicity and tissue response to a biomaterial which could be applied as an ideal wound dressing. Human amniotic membrane used was derived from one individual and was obtained from the Biomaterial Center and Tissue Bank in Dr. Soetomo General Hospital Surabaya Indonesia while the glutaraldehyde used was a commercial product. The wound dressing from human amniotic membrane-glutaraldehyde was made by dipping the human amniotic membrane with a solution of different variation of glutaraldehyde compositions, ie $0: 25 \%, 0.5 \%$, $0.75 \%, 1 \%$, and $1.25 \%$. The results of the research also found the $\mathrm{pH}$ measurements on human amnion membrane-glutaraldehyde according to skin balance range (4.0-7.0) by adding $0.25 \%, 0.5 \%$, $0.75 \%, 1 \%$, and $1.25 \%$ glutaraldehid to human amniotic membrane. FTIR characterization test results indicate the change of intensity of tertiary amine group $(\mathrm{C}-\mathrm{N})$ in the human amniotic membrane-glutaraldehyde by $0,25 \%, 0,5 \%, 0.75 \%, 1 \%$, and $1.25 \%$ glutaraldehyde concentration. The best concentration of glutaraldehyde to be applied as wound dressing was at a concentration of $1 \%$, which was based on the results of tensile test $26.67 \mathrm{MPa}$, percentage of living cell in the cytotoxicity assay of $113.483 \%$, and Histopathology Anatomy test that shows $100 \%$ of wound reepithelialization on the mice's skins.
\end{abstract}

\section{Introduction}

Tissue engineering techniques are having an increase in importance as the number of accidents, fires, surgical cesarean birth, and the events that lead to injury are increasing. Amniotic membrane is considered to have a good ability as a biomaterial, especially as a wound dressing. Amniotic membrane has the ability as an ideal wound dressing due to its structure and biological capabilities that could be ideal candidates for a wound dressing. Amniotic membrane has good properties such as anti-inflammatory, anti-microbial, anti-fibrotic, anti-scarring, and low immunogenicity.

The amnion membrane is one of the biomaterial that can be used as material for the transplantation of skin and wound dressing. The use of amniotic tissue as the skin transplant was first reported in 1910 [1]. In 1913, Sabella used the amniotic membrane on the surface of a burned and ulcerated skin, and she observed reduction in infection that is characterized by a decrease in pain and an increase in the rate of re-epithelialization of the traumatic skin surface. These biomaterials have varied use in the field of ophthalmology, burns, and in general surgical procedures to reduce adhesion, minimize inflammation, and as a temporary cover that facilitates natural reconstruction and repair of scar tissue [2].

Amniotic membrane is biomembrane with many uses which have been widely used in clinical applications, such as closing of burns, wound dressing, and others [3]. Amniotic membrane is an avascular tissue that is pliable yet durable [4]. Human amniotic membrane has a tensile 
strength of $0.069-0.03 \mathrm{MPa}$ [5]. The inside of the membrane associated with fluids is cuboidal cells which originate from the ectoderm. This network is associated with interstitial layer which contains collagen I, III, IV [4].

Amniotic membrane has some good properties to be used as a wound dressing, among others, are anti-inflammatory and antibacterial as well as low immunogenicity. Amniotic membrane regulates the formation of Transforming Growth Factor Beta (TGF- $\beta$ ) and receptor expression by fibroblasts in order to reduce the risk of fibrosis caused by TGF- $\beta$ transformation. Therefore, amniotic membrane can modulate wound healing by promoting the reconstruction of the tissue rather than to promote the formation of scar tissue [6] [7].

There are some researches that confirm the anti-inflammatory capabilities of amniotic membrane. Stroma matrix in amniotic membrane suppresses the expression of strong proinflammatory cytokines, IL-1 $\alpha$ and IL-1 $\beta$ [8]. Metalloproteases matrix (MMPs) is expressed by infiltrating PMN cells and macrophages. Natural inhibitors of MMPs have been found in amniotic membrane [9] [10]. Hyaluronic Acid is a high molecular weight glycosaminoglycans which present in large quantities and acts as a ligand for CD44, which is expressed on inflammatory cells and plays an important role in the adhesion of inflammatory cells, including lymphocytes in the stroma membrane [11].

Anti-microbacterial nature of amniotic membrane can be known from some of the results of existing research. Amniotic membrane has E cystatin, an analog of cysteine proteinase inhibitor, which demonstrates antivirus properties [12]. Amnion and chorionic also have antimicrobial effects against certain microorganisms [13].

Glutaraldehyde is one of cross-linked agents derived from aldehid, an alkane derivative compound. Although glutaraldehyde has an active power which is more effective than other aldehyde derivatives, glutaraldehyde is not potentially carcinogenic if added to its threshold. Glutaraldehyde which commonly used as a disinfectant material is also able to enhance biological properties such as antibacterial which prevents inflammation [14].

One of the requirements of other wound closure is having the same mechanical properties to the skin. A strong tensility on the human skin is in the range of 5-32 $\mathrm{MPa}$ [15]. Human amniotic membrane has a tensile strength of $0.069-0.03 \mathrm{MPa}$ [16]. A physical properties improvement is needed for the lack of mechanical properties in terms of tensile strength comparisons between human amniotic membranes and human skin, so that the human amniotic membrane can be more biocompatible with the human skin upon application as wound dressing.

In recent years, there is a large number of research groups that aim to generate and improve the properties of wound dressing [17] [18]. Treatment with glutaraldehyde is expected to improve the physical properties, such as tensile strength of the human amniotic membrane by forming cross-linking of collagen contained in the human amniotic membrane, to obtain material that can be stored for easy use. An example is the study conducted by Spoerl [19] which founds that providing treatment with $0.1 \%$ glutaraldehyde can significantly improves biomechanical properties, which indicated by significant statistical increase by $175 \%$ in tensile test compared with fresh amniotic and 76.8\% with cryopreserved amniotic [19]. Amniotic membrane treated with 1\% glutaraldehyde can prevent inflammation [20].

When glutaraldehyde crosslinked with collagen, they would form a tertiary amine which can be identified from the existence the C-N stretching vibration at $1350-1000 \mathrm{~cm}^{-1}$ wave number which has a medium-strong peak intensity, while the tertiary amine's N-H stretching vibration cannot be identified in the area of $3500-3300 \mathrm{~cm}^{-1}$ wave number [21].

Based on researches conducted by Spoerl [19] which used the addition of glutaraldehyde at $0.1 \%$ concentration and Samaniego [20] which added $1 \%$ concentration in the amniotic membrane, a research on wound dressing synthesis needs to be done to find the characteristics of a good wound dressing. The research should be based on human amniotic's glutaraldehyde-membrane with glutaraldehyde concentration variation in the range of $0.1 \%$ and $1 \%$, which are $0.25 \%, 0.5 \%, 0.75 \%$, $1 \%$, and $1.25 \%$. Biomechanical strength tests such as tensile test, cytotoxicity material test, and histopathology anatomy testing needs to be done in order to obtain an amniotic membraneglutaraldehyde mixture that is biocompatible with human skin. 


\section{Materials and Method}

Materials used for the manufacture and testing of the mixture of human amniotic membrane-glutaraldehyde include human amniotic membrane derived from the placenta of the individual, gauze, saline solution $0.9 \%$, glutaraldehyde $25 \%$, distilled water, 2 months old male mice weighing 20-30 grams, and histopathological anatomy test materials.

The tools used to manufacture the mixture of human amniotic membrane-glutaraldehyde were glass beaker, measuring cup, spatula, tounge spatel, digital balance, circular pan, bowl, scissors, ruler, lyophilizer, $-80^{\circ}$ deep freezer, and laminar air flow. The mixture testing used a set of Fourier Transform Infra Red (FTIR) instrumentation tools Shimadzhu with 300-4000nm wavelength, digital micrometer, Tensile Strength test equipment, a set of cell culture tools, Elisa Reader, and Olympus Optical Japan electron microscope.

\section{Procedure}

\section{The Preparation of the Glutaraldehyde Solution}

Dissolving $5 \mathrm{ml}, 10 \mathrm{ml}, 15 \mathrm{ml}, 20$ and $25 \mathrm{ml}$ of $25 \%$ glutaraldehyde with distilled water in a $500 \mathrm{ml}$ volumetric flask was performed to make a glutaraldehyde solution in this study. As a result of the dilution, glutaraldehyde solutions with variation of $0 \%, 0.25 \%, 0.5 \%, 0.75 \%, 1 \%$ and $1.25 \%$ were obtained. Figure 3.2 is a preparation for the glutaraldehyde solutions with concentration addition variation ranging from $0.25 \%$ to $1.25 \%$.

\section{The Preparation of Amniotic Membrane}

Amniotic membrane preparation procedures in this study was done by removing chorion fluid from the amniotic membrane which had been prepared by pressing and rubbing tounge spatula on amniotic membrane. After the amniotic membrane was free of chorion, amniotic membrane was washed three times by using $0.9 \%$ saline solution with a maximum washing time of 5 minutes.

\section{The Preparation of Amniotic Membrane-Glutaraldehyde Mixture}

The amniotic membrane which had been washed with $0.9 \%$ saline solution is cut to six and treated with a solution of glutaraldehyde with a variety of solution volume of $0 \%, 0.25 \%, 0.5 \%$, $0.75 \%, 1 \%$ and $1.25 \%$. The treatment was given by dipping into the amniotic membrane of each solution of glutaraldehyde with the exposure time for 15 minutes. After dyeing with glutaraldehyde, amniotic membrane was washed three times with $0.9 \%$ saline solution with a maximum time of 5 minutes.

After it had been washed, the amniotic membrane was being glued to the gauze that had been overlaid on a baking sheet by stretching the membrane. After that, the amniotic membrane's PH was measured by using Universal indicator. It was done to determine the degree of acidity of human amniotic membrane, because the degree of acidity will affect the value of comfort in its application as a wound dressing. After the measurement of human amniotic membrane's $\mathrm{pH}$, it was then inserted into the $-80^{\circ} \mathrm{C}$ deep freezer for 18 hours then sublimed with lyophilizer for 6 hours.

\section{FTIR Test}

The amnion membrane-glutaraldehyde mixture was pulverized and then stirred with $\mathrm{KBr}$ powder together in one bowl until smooth and even texture appeared, then it was shaped at a certain pressure level to produce a thin transparent pellets. Characterization of the sample pieces was done by using Shimadzu FTIR spectrometer at 4000-300 $\mathrm{cm}^{-1}$ wavelength. Infra red result was obtained in the form of spectrum which describes the value of the transmittance percentage (\% $\mathrm{T})$ and wave number $\left(\mathrm{cm}^{-1}\right)$, so that the functional groups contained in the membranes mixture could be identified. 


\section{Tensile Test}

Determination of the mechanical properties was done by cutting the membrane consistent with the shape of the tensile test bars. Then the membrane thickness was measured with a digital micrometer. The ends of the membrane were attached to the test equipment and towing load was mounted in kgf unit. Membrane was splayed on a certain velocity until it was cut. Based on the results, the value of the ultimate tensile strength was obtained from the sample materials.

\section{Cytotoxicity Test}

BHK 21 cells with a density of $2 \times 105$ was dissolved in $100 \mu \mathrm{L}$ of media $(6 \%$ media eagle's, $1 \%$ penicillin streptomycin, fungizone 100 units $/ \mathrm{mL}$ ), and then transferred into 96-microwell plate. Amniotic membrane which was cut by $1 \times 1 \mathrm{~cm}$ sterilized with UV light for longer than one night. Then 0.05 gram of sample was dissolved in $1 \mathrm{ml}$ of ethanol. The sample solution was then inserted in $50 \mu \mathrm{L}$ 96-microwell plate. Then it was incubated for 24 hours at $37^{\circ} \mathrm{C}$. The tool which was used to calculate the optical density value of formazan is ELISA reader.

\section{Histopathology Anatomy Test}

Experimental animals used were 2 months old male mice weighing 20-30 grams. The process of data collection was done by wounding the mice by performing incisions and then closing the wound with a mixture of amniotic membrane with some variation of the concentrations of glutaraldehyde. The taking of the mouse skin to proceed to the process of preparation of the histopathology anatomy performed on days 3, 5, and 7. The mice which had their skins excised were then fixed with a solution of $10 \%$ BNF (Buffer Neutral Formaline) for \pm 48 hours. After fixation, tissue processing was done by dehydrating with graded alcohol concentration, clearing, and paraffin infiltration with tissue processor machine. The next process was the manufacture of blocks (embedded blocks) using paraffin, making preparations for the tissue, deparafination, coloring, closing (mounting), then the last phase was the observation using a Olympus Optical Japan microscope.

\section{Result and Discussion}

\section{FTIR Test Result}

From the physical chemistry test using FT-IR spectrophotometer, it was known that human amniotic membrane-glutaraldehyde showed characteristic absorptions group that was a tertiary amine. From Table 1, it was known that there was an intensity of absorption at $1242.16 \mathrm{~cm}^{-1}$ wave number which shows the $\mathrm{C}-\mathrm{N}$ bond stretching vibration, it was in accordance with the range of wave numbers mentioned by Pavia et al [21], while the $3309.85 \mathrm{~cm}^{-1}$ wave number shows the existence of stretching amine vibration $(\mathrm{NH})$. This suggests that the presence of a tertiary amine group formed of the crosslinking cannot be identified because of the collagen that may affect the reading of a tertiary amine group.

Collagen that is composed by many amino acids was what actually reads at the $3309.85 \mathrm{~cm}^{-1}$ wave number. Therefore, further testing was needed to determine the detailed structure of the crosslinking groups formed by conducting the Nuclear Magnetic Resonance (NMR) test. C-N group intensity indicates the number of crosslinks formed on the human amniotic membraneglutaraldehyde mixture. Irregular changes of groups' intensities along with glutaraldehyde addition were made possible because of the pelletizing process was not done quantitatively. 
Table 1. Data of FTIR Results Wave Numbers in Human Amniotic Membrane-Glutaraldehyde Mixture

\begin{tabular}{|c|c|c|c|c|c|}
\hline \multirow[t]{2}{*}{ Sample } & \multirow{2}{*}{$\begin{array}{c}\text { Variation of } \\
\text { Glutaraldehyde } \\
\text { Addition } \\
\text { Concentrations }\end{array}$} & \multicolumn{2}{|c|}{ C-N } & \multicolumn{2}{|c|}{ N-H } \\
\hline & & $\begin{array}{c}\text { Wave } \\
\text { Number } \\
\left(\mathrm{cm}^{-1}\right)\end{array}$ & Intensity & $\begin{array}{c}\text { Wave } \\
\text { Number } \\
\left(\mathrm{cm}^{-1}\right)\end{array}$ & Intensity \\
\hline A & $0 \%$ & 1242.16 & 25.873 & 3309.85 & 10.161 \\
\hline $\mathrm{B}$ & $0.25 \%$ & 1242.16 & 10.347 & 3309.85 & 1.256 \\
\hline $\mathrm{C}$ & $0.5 \%$ & 1242.16 & 12.438 & 3309.85 & 1.434 \\
\hline $\mathrm{D}$ & $0.75 \%$ & 1242.16 & 10.226 & 3309.85 & 0.907 \\
\hline $\mathrm{E}$ & $1 \%$ & 1242.16 & 8.728 & 3309.85 & 0.677 \\
\hline $\mathrm{F}$ & $1.25 \%$ & 1242.16 & 15.085 & 3309.85 & 1.964 \\
\hline
\end{tabular}

The effect of glutaraldehyde on amniotic membrane related on chemical interaction namely crosslinking At the early stage, the cross-linking reaction could to decrease the mobility of protein molecules and to conduct barriers to cross-linker infiltration [22].

\section{Tensile Test Result}

The increase in tensile strength in Figure 1 shows that the addition of the composition variation of $0.25 \%$ to $1.225 \%$ glutaraldehyde can increase the tensile strength of the human amniotic membrane. Based on Vogel's research in 1987, Ultimate Tensile Strength in human skin on various spots is ranging from 5-32 $\mathrm{MPa}$, the result of the addition of glutaraldehyde at suitable amniotic membrane is at the range of $0.25 \%$ to $1 \%$ concentration. The increase in tensile strength in the human amniotic membrane-glutaraldehyde mixture was caused by the ability of glutaraldehyde as crosslinking collagen found in amniotic membrane [19]. Collagen crosslinking induces the interand intrafibrillar covalent and led to an increase in biomechanical strength. The more crosslinking occured, the greater the force required to break the crosslink. That makes the value of tensile strength grew [23]. Glutaraldehyde stimulate to great increase in the biomechanical strength and enzymatic resistance of amnion [19].

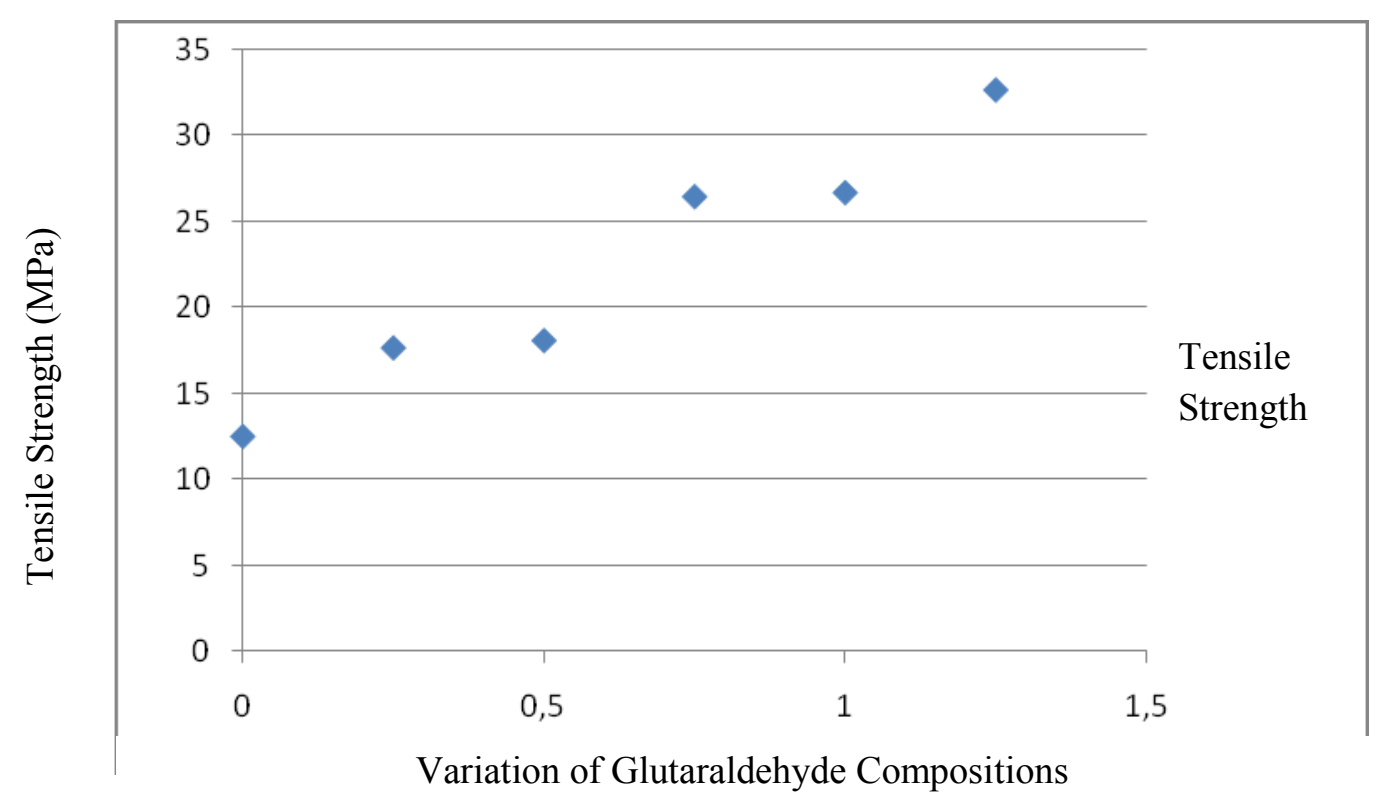

Figure 1. The Relationship between the Variation of Glutaraldehyde Compositions with the Tensile Strength 


\section{Cytotoxicity Test Results}

Table 2 showed that the live cells percentage of sample A is $116.629 \%, 118.938 \%$ for sample B, $114.382 \%$ for sample C, $119.169 \%$ for sample D, $113.483 \%$ for sample E, and $115.012 \%$ for sample $\mathrm{F}$. The percentage of live cells above $100 \%$ in the whole sample showed that the human amniotic membrane and glutaraldehyde used as the raw materials for the manufacture of human amniotic membrane-glutaraldehyde were safe to be used as wound dressings because they are not toxic to fibroblasts. A material is said to be toxic if the percentage of cells that live are less than $50 \%$ [24].

Table 2. Percentage of Living Cells

\begin{tabular}{|c|c|c|}
\hline Sample & Variation of Glutaraldehyde Addition Concentrations & Live Cells \% \\
\hline A & $0 \%$ & 116.629 \\
\hline B & $0.25 \%$ & 118.938 \\
\hline C & $0.5 \%$ & 114.382 \\
\hline D & $0.75 \%$ & 119.169 \\
\hline E & $1 \%$ & 113.483 \\
\hline F & $1.25 \%$ & 115.012 \\
\hline
\end{tabular}

\section{Histopathology Anatomy Test Results (HPA)}

The parameter observed in this study is re-epithelialization percentage. Re-epithelialization level of an injury is one of the parameters of the process of repair of epithelial cells of the skin which caused the closing of a wound. The faster the re-epithelialization happened, the faster the structure of the epidermis and the skin back to its normal condition. The results of microscope observations on the prepared mice's wounds after treated with a human amniotic membrane mixture in the amount of $100 \mathrm{x}$ are as follows:
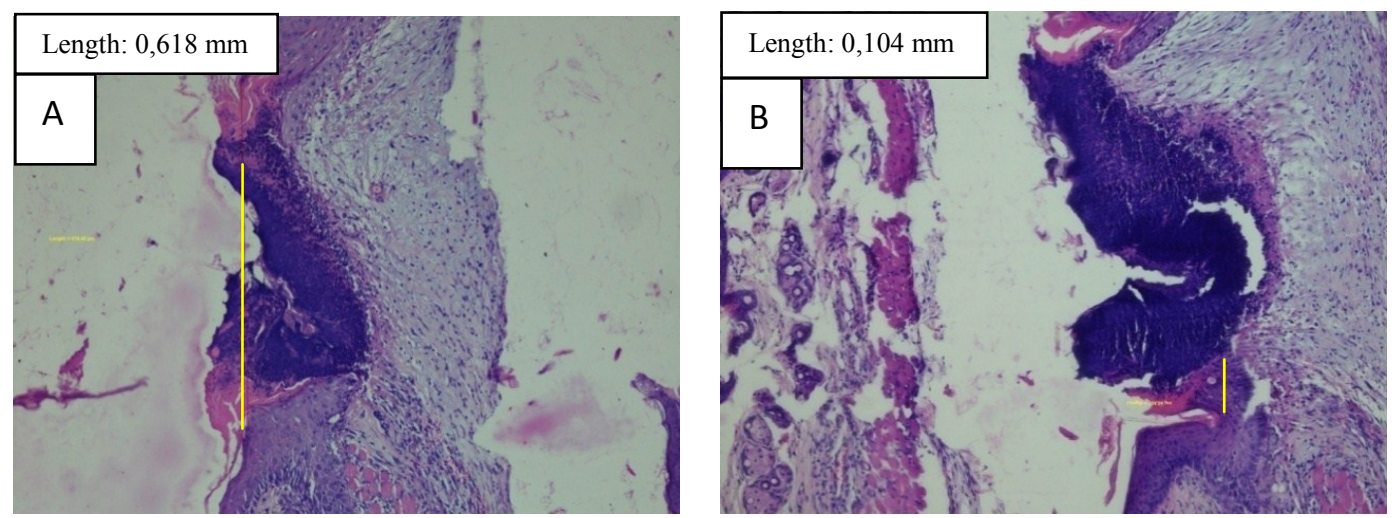

Figure 2. A.The total length of the wound on histopathology anatomy test result in the addition of $0 \%$ glutaraldehyde (A) on the $5^{\text {th }}$ day. B.The re-epithelization length of the wound on histopathology anatomy test result in the addition of $0 \%$ glutaraldehyde $(\mathrm{A})$ on the $5^{\text {th }}$ day
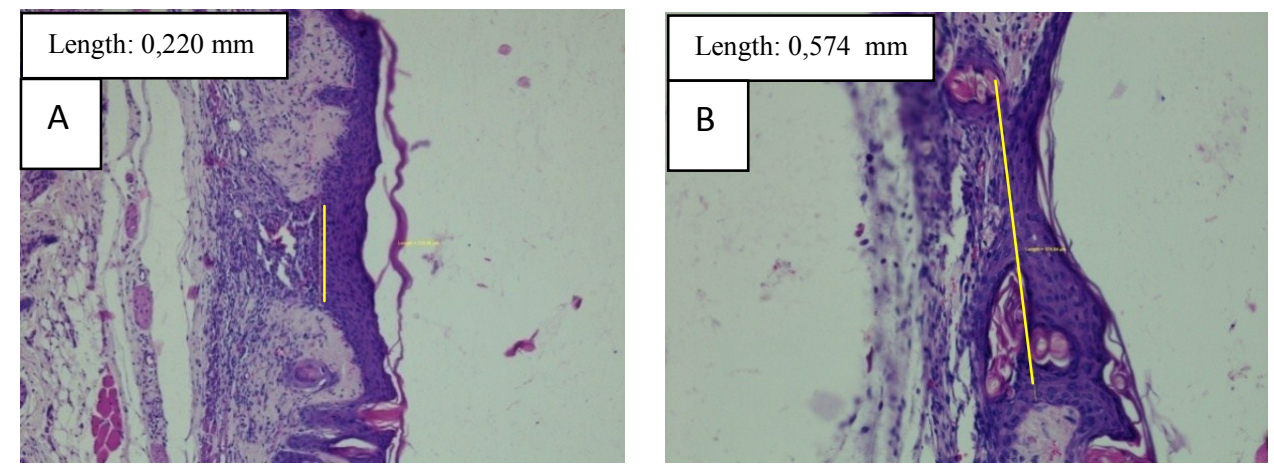


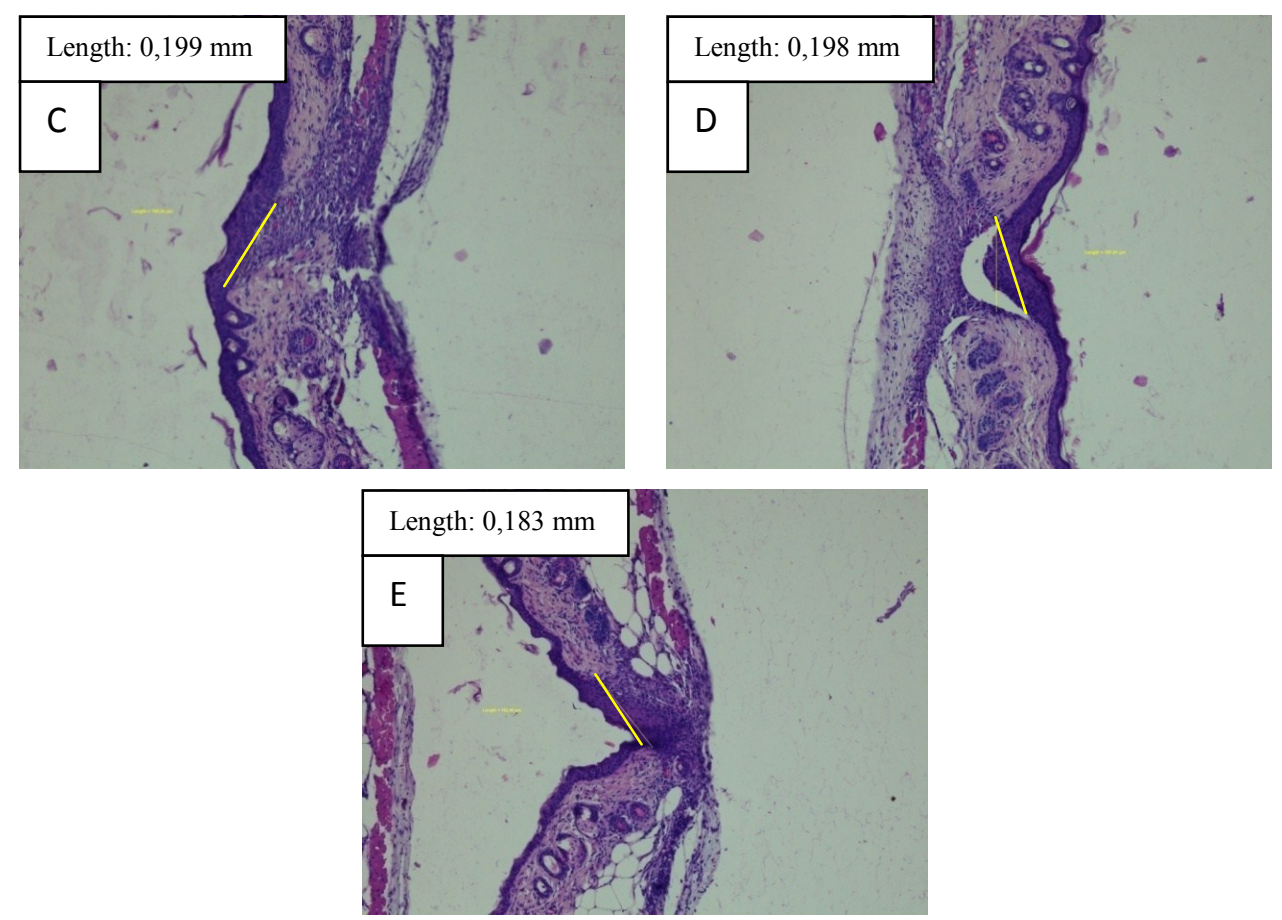

Figure 3. A.The re-epithelization length of the wound on histopathology anatomy test result in the addition of $0.25 \%$ glutaraldehyde $(\mathrm{B})$ on the $5^{\text {th }}$ day $\mathbf{B}$. The re-epithelization length of the wound on histopathology anatomy test result in the addition of $0.5 \%$ glutaraldehyde $(C)$ on the $5^{\text {th }}$ day $\mathbf{C}$. The re-epithelization length of the wound on histopathology anatomy test result in the addition of $0.75 \%$ glutaraldehyde (D) on the $5^{\text {th }}$ day $\mathbf{D}$. The re-epithelization length of the wound on histopathology anatomy test result in the addition of $1 \%$ glutaraldehyde (E) on the $5^{\text {th }}$ day E.The re-epithelization length of the wound on histopathology anatomy test result in the addition of $1.25 \%$ glutaraldehyde on the $5^{\text {th }}$ day

Table 3. Re-epithelialization Percentage

\begin{tabular}{|c|c|c|c|c|c|}
\hline \multirow{2}{*}{ Sample } & \multirow{2}{*}{$\begin{array}{c}\text { Variation of Glutaraldehyde } \\
\text { Addition Concentrations }\end{array}$} & Day & \multicolumn{2}{|c|}{ Wound's Width (mm) } & \multirow{2}{*}{$\begin{array}{c}\text { Re- } \\
\text { epithelialization } \\
\text { Percentage }\end{array}$} \\
\cline { 4 - 5 } & & $5 \%$ & Total & $\begin{array}{c}\text { Closed by } \\
\text { Epithelium }\end{array}$ & \\
\hline A & $0.25 \%$ & 5 & 0.220 & 0.104 & $20.233 \%$ \\
\hline B & $0.5 \%$ & 5 & 0.574 & 0.574 & $100.000 \%$ \\
\hline C & $0.75 \%$ & 5 & 0.199 & 0.199 & $100.000 \%$ \\
\hline D & $1 \%$ & 5 & 0.198 & 0.198 & $100.000 \%$ \\
\hline E & $1.25 \%$ & 5 & 0.183 & 0.183 & $100.000 \%$ \\
\hline F & & 5 & & \\
\hline
\end{tabular}

Re-epithelialization percentage data can be seen in Table 3. Observation results on preparation with a microscope at 100x magnification. Re-epithelialization percentage table was calculated. Sample A preparation is preparation of skin wounds of mice after treatment with amniotic membrane without glutaraldehyde, showed that on the fifth day, the readable re-epithelialization percentage of $20.233 \%$, it indicates the re-epithelialization occured was incomplete. In the preparations B, C, D, E, and F, the wounds on mice's skins had been 100\% re-epithelialized. The formation of this epithelium can be observed from the growth

The formation of epithelium can be observed from the growth of epithelium across the whole wound surface. On the preparation, wound can be observed from the tissue's discontinuity. "Wound" is a condition of the absence or the damage on the tissue's continuity [25]. The high percentage of re-epithelialization in the wounds that covered with human amniotic membraneglutaraldehyde is because the amniotic membrane serves as a basal membrane that facilitates the migration of epithelial cells, strengthen the cell adhesion of basal epithelial, promoting the 
differentiation of epithelial and prevent apoptosis of epithelial, [26] and the addition of glutaraldehyde at a concentration of $0.25 \%$ to $1.25 \%$ did not give a negative response, because it does not interfere with the process of re-epithelialization.

\section{Conclusion}

1. The glutaraldehyde at a concentration of $0.25 \%$ to $1.25 \%$ indicated the change of $\mathrm{C}-\mathrm{N}$ bond intensity in the FTIR spectrum and the increaseof Ultimate Tensile Strength. The material wa non toxic due to the percentage of living cells of amniotic membrane-glutaraldehyde. Histopathology anatomy (HPA) test results showed re-epithelialization percentage of $100 \%$ in the wound site.

2. Wound dressing with the best characteristic was obtained from $1 \%$ glutaraldehyde to human amniotic membrane due to the $\mathrm{pH}$ which in the range of skin's $\mathrm{pH}$ balance of 6 , tensile strength, cytotoxicity test result and histopathological anatomy test results.

\section{References}

[1] Davis, J. W. 1910. Skin transplantation with a review of 550 cases at the Johns Hopkins Hospital. Johns Hopkins Med J 15: 307.

[2] Trelford JD, Trelford Suaer M. 1979. The amnion in surgery, past and present. Am J Obstet Gynecol;134:833-845.

[3] Yin, Lan and Yu-Li Pi. 2011. Effect of amnion membrane transplantation on corneal neovascularization in 10 patients with alkali burn. China: Int J Opthalmol

[4] Niknejad, Hassan, et al. 2008. Properties of Amniotic Membrane for Potential Use in Tissue Engineering. European Cells and Materials Vol. 15 pages 88-99.

[5] Peng, Chuangang, et al. 2012. Strain and stress variations in the human amniotic membrane and fresh corpse autologous sciatic nerve in a model of sciatic nerve injury. China: Neural Regeneration Research.

[6] Tseng SC, Li DQ \& Ma X. 1999. Suppression of transforming growth factor-beta isoforms, TGF-beta receptor type II, and myofibroblast differentiation in cultured human corneal and limbal fibroblasts by amniotic membrane matrix. J Cell Physiol

[7] Lee SB, Li DQ, Tan DT, Meller DC, Tseng SC. 2000. Suppression of TGF-beta signaling in both normal conjunctival fibroblasts and pterygial body fibroblasts by amniotic membrane. Curr Eye Res 20: 325-334.

[8] Solomon A., et al. 2001. Suppression of interleukin 1 $\alpha$ and interleukin $1 \beta$ in human limbal epithelial cells cultured on the amniotic membrane stromal matrix. Br J Ophthalmol; 85:444449.

[9] Hao Y., et al. 2000. Identification of antiangiogenic and anti-inflammatory proteins in human amniotic membrane. Cornea;19:348-352.

[10] Kim, J. S., et.al. 2000. Amniotic membrane patching promotes healing and inhibits proteinase activity on wound healing following acute corneal alkali burn. Exp Eye Res;70:329-337.

[11] Higa, K., et al. 2005. Hyaluronic acid-CD44 interaction mediates the adhesion of lymphocytes by amniotic membrane stroma. Cornea 24: 206-212.

[12] Ni J., et al. 1997. Cystatin E is a novel human cysteine proteinase inhibitor with structural resemblance to family 2 cystatins. J Biol Chem; 272:10853-10858.

[13] Kjaergaard N., et al. 2001. Antibacterial properties of human amnion and chorion in vitro. Eur J Obstet Gynecol Reprod Biol;94:224-229. 
[14] Widyatama, D. 2011. Efektifitas Kombinasi Glutaraldehid dan Didecil Dimetil Amonium Klorida sebagai Desinfektan Terhadap Penurunan Jumlah Bakteri pada Kandang Ayam Layer. Surabaya: Airlangga University.

[15] Vogel, H. 1987. Age dependence of mechanical and biochemical properties of human skin. Bioengineering and the skin 3, 67-91

[16] Peng, Chuangang, et al. 2012. Strain and stress variations in the human amniotic membrane and fresh corpse autologous sciatic nerve in a model of sciatic nerve injury. China: Neural Regeneration Research.

[17] Shitaba H., Shioya N., Kuroyangi Y. 1997. Development of New Wound Dressing Composed of Spongy Collagen Sheet Containing Dibutyryl Cyclic AMP. J Biomater Sci Polym Ed 1997; 8:601-21.

[18] Draye, JP. Delaey B., Van den Voorde A., De Reu B., Schact E. 1998. In Vitro and In Vivo Biocompatibility of Dextran Dialdehyde Cross-Linked gelatin Hydrogel Film. Biomaterials 1998; 19: 1677-87.

[19] Spoerl E, Wollensak G, Reber F, Pillunat L, 2004. Cross-linking of human amniotic membrane by glutaraldehyde.Ophthalmic Res. 2004 Mar- Apr;36(2):71-7.

[20] Samaniego , A.S., et al. 2009. Human Amnion Tissue as an Anti-adhesion, Anti-inflammatory Barrier in an Ovine Laminectomy Model. Colorado State University, Ft. Collins.CO: USA

[21] Pavia, et al.2009. Introduction to Spectroscopy $4^{\text {th }}$ edition. Washington: Brooks/Cole Cengage Learning.

[22] Jui-Yang lai, David hui-Kang Ma, 2013. Glutaraldehyde cross-linking of amniotic membranes affects their nanofirous structures and limbal epithelial cell culture characteristics. International Journal of Nanomedicine 2013 8 : 4157-4168

[23] Weadock KS, Miller EJ, Keuffel EL, Dunn MG. 1996. Effect of physical crosslinking methods on collagen-fiber durability in proteolytic solutions. J Biomed Mater Res;32:221-226.

[24] Spielmann, H., et al. 2007. The ECVAM International Validation Study on In VitroTests for Acute Skin Irritation: Report on the Validity of the EPISKIN and EpiDerm Assays and on the Skin Integrity Function Test. Germany: ATLA.

[25] Mansjoer, Arif, dkk. 2000. Kapita Selekta Kedokteran Edisi III. Faculty of Medicine of University of Indonesia: Aescullapius.

[26] Baradaran-Raffi, A., et al. 2007. Amniotic Membrane Transplantation. IRANIAN JOURNAL OF OPHTHALMIC RESEARCH 2007; Vol. 2, No. 1 